\title{
ASTHMA
}

\section{Relationship between induced sputum eosinophils and the clinical pattern of childhood asthma}

\author{
P G Gibson, J L Simpson, R Hankin, H Powell, R L Henry
}

Thorax 2003;58:1 16-121

See end of article for authors' affiliations

Correspondence to: A/Prof P G Gibson

Department of Respiratory and Sleep Medicine, John

Hunter Hospital, Locked

Bag 1, Hunter Region Mail

Centre, NSW 2310,

Australia;

mdpgg@

mail.newcastle.edu.au

Revised version received

11 September 2002

Accepted for publication

2 October 2002
Background: The relationship between the clinical pattern of asthma and airway inflammation in childhood asthma is poorly characterised, yet underpins the treatment recommendations in current asthma guidelines. A study was undertaken to examine the relationship between airway inflammation and clinical asthma in children.

Methods: Children with asthma $(n=146)$ and healthy controls $(C, n=37)$ were recruited from primary and specialist clinics. Sputum induction and hypertonic saline challenge were performed.

Results: As the frequency of asthma episodes in the past 12 months increased, there were significant increases in sputum eosinophils (median; infrequent episodic (IE) $1.5 \%$, frequent episodic (FE) $2.3 \%$, persistent (P) 3.8\%, control (C) 1.0\%; $\mathrm{p}=0.002)$, sputum eosinophil cationic protein (ECP) (IE $113 \mathrm{ng} /$ $\mathrm{ml}$, FE 220, P 375, C 139; $\mathrm{p}=0.003$ ), and desquamated bronchial epithelial cells (IE 2.0\%, FE 6.0\%, P 5.0\%, C 2.5\%; $\mathrm{p}=0.04$ ). Treatment intensity was also associated with increased sputum eosinophils $(p=0.005)$. The relationships between other severity markers (current symptoms, lung function) were less strong.

Conclusion: Children with more frequent episodes of clinical asthma exhibit increasing airway inflammation that is characterised by sputum eosinophilia and bronchial epithelial desquamation. The results support clinical assessment by frequency of wheezing episodes over the past 12 months when determining anti-inflammatory treatment requirements, and indicate that current symptoms are determined by mechanisms in addition to sputum eosinophilia.
A sthma is a chronic inflammatory disorder of the airways in which the clinical pattern can be assessed based on the frequency of episodes. ${ }^{1}$ This classification is used to recommend the dose and type of anti-inflammatory treatment. ${ }^{1}$ The underlying assumption in this and other guidelines is that airway inflammation is linked to the clinical asthma pattern, and that airway inflammation increases as the clinical activity increases.

Studies which directly examine these assumptions have produced mixed results. In some studies, although sputum eosinophils were increased in children with asthma compared with healthy controls, inflammatory markers were not related to asthma severity. ${ }^{2-4}$ Other studies have found a weak relationship between symptoms and sputum eosinophils in patients with very mild asthma, ${ }^{5}$ and a non-significant trend for increasing sputum eosinophils with increasing current symptoms ${ }^{67}$ or asthma severity. ${ }^{8}$ These disparate results may relate to limited study sample size, selection of subjects from predominantly referral clinics, and the use of differing clinical classifications. We therefore sought to characterise the relationship between clinical asthma and airway inflammation in a large group of asthmatic children with a broad range of clinical disease recruited from both primary care and specialist clinics.

\section{METHODS}

Children with a diagnosis of asthma were recruited from respiratory clinics at John Hunter Children's Hospital, from general paediatricians, and general practice. Children were eligible if they were at least 6 years of age, had a definite diagnosis of asthma, and were being reviewed on a routine basis for their asthma. Two general paediatricians and a GP with an interest in asthma were approached to refer children for study. In addition, the control children and other children with asthma were recruited from general practice as part of a project assessing the computer based diagnosis of asthma. ${ }^{9}$ Controls were randomly sampled and asthma was excluded on the basis of history, normal spirometric findings, and airways responsiveness, together with data review by a specialist. Following informed consent, a clinical asthma questionnaire was completed and spirometric tests were performed followed by hypertonic saline challenge and sputum induction.

Written informed consent was obtained from parents and children. The study was approved by the Hunter Area Research ethics committee and the University of Newcastle ethics committee.

\section{Clinical classification of asthma}

A diagnosis of asthma was made based on a history of current (past 12 months) episodic respiratory symptoms, a previous doctor's diagnosis of asthma (ever), and the current (past 12 months) use of inhaled asthma treatment $\left(\beta_{2}\right.$ agonists, corticosteroids or cromolyn). A clinical asthma questionnaire ${ }^{6}$ was completed for each child by interviewing the parent.

The pattern of clinical asthma over the previous 12 months was categorised according to the frequency of symptomatic episodes,${ }^{19}$ irrespective of treatment. Children with infrequent episodic asthma had $<6$ attacks per year, children with frequent episodic asthma had $\geqslant 6$ attacks in the past 12 months, and children with persistent asthma experienced asthma symptoms on most $(\geqslant 3)$ days each week. These cut off points were based on a prior analysis of questionnaire responses in comparison with respiratory paediatrician diagnosis of asthma. ${ }^{9}$

Asthma treatment was classified into three major groups: no preventative treatment, inhaled preventers (sodium cromoglycate and corticosteroids), and oral corticosteroid therapy. Asthma symptoms were also evaluated over the previous 2 weeks and classified as currently symptomatic based on the presence of wheeze, the presence of nocturnal waking 
Table 1 Characteristics of children with asthma and healthy controls

\begin{tabular}{|c|c|c|c|c|c|}
\hline & Infrequent episodic & Frequent episodic & Persistent & Healthy control & $\mathrm{p}$ value \\
\hline $\mathrm{n}$ & 72 & 39 & 35 & 37 & \\
\hline Mean (SD) age (years) & $11(2.8)$ & $11(3.4)$ & $12(2.6)$ & $11(3.1)$ & 0.126 \\
\hline Sex $(\%$ male $)$ & $70 \%$ & $56 \%$ & $68 \%$ & $43 \%$ & 0.04 \\
\hline \multicolumn{6}{|c|}{ Current asthma symptoms, \% (past 2 weeks) } \\
\hline Missed school & $8 \%$ & $13 \%$ & $29 \%$ & $0 \%$ & 0.05 \\
\hline Increased wheeze & $21 \%$ & $38 \%$ & $54 \%$ & $0 \%$ & 0.0001 \\
\hline Night waking & $10 \%$ & $32 \%$ & $59 \%$ & $0 \%$ & 0.0001 \\
\hline Morning waking & $9.7 \%$ & $27 \%$ & $41 \%$ & $0 \%$ & 0.0003 \\
\hline Nights woken, median (IQR) & $1.0(1,1)$ & $1.5(1,7)$ & $2.0(1,6)$ & $0(0)$ & 0.462 \\
\hline Morning woken, median (IQR) & $1.0(1,1)$ & $5.0(1.5,7)$ & $1.0(1.0,1.0)$ & $0(0)$ & 0.061 \\
\hline \multicolumn{6}{|l|}{ Treatment (\% using) } \\
\hline Cromoglycate & $14 \%$ & $18 \%$ & $26 \%$ & 0 & 0.325 \\
\hline ICS & $58 \%$ & $82 \%$ & $83 \%$ & 0 & 0.006 \\
\hline Oral corticosteroid & $3 \%$ & $10 \%$ & $20 \%$ & 0 & 0.01 \\
\hline Median (IQR) daily dose ICS ( $\mu \mathrm{g})$ & $0(0-400)$ & $400(0-775)$ & $400(100-1000)$ & 0 & $<0.01$ \\
\hline \multicolumn{6}{|l|}{ Mean (SD) asthma history $\ddagger$} \\
\hline Duration of asthma (years) & $7.3(3.7)$ & $8.8(3.6)$ & $9.6(3.3)$ & NA & 0.008 \\
\hline Missed school (days) & $5.8(4.7)$ & $11.1(10.8)$ & $20.4(15.8)$ & NA & 0.0001 \\
\hline Exacerbations $(\mathrm{n})$ & $2.2(1.7)$ & $4.6(3.4)$ & $7.4(6.8)$ & NA & 0.0001 \\
\hline GP visits (n/year) & $3(4.3)$ & $6.2(5.9)$ & $10.9(13.0)$ & NA & 0.0001 \\
\hline Admissions ( $\mathrm{n} /$ year) & $1.0(0.5)$ & $2.4(2.1)$ & $2.3(1.6)$ & NA & 0.164 \\
\hline Exacerbations (days in past year) & $17.1(32.9)$ & 29.4 (31.9) & 59.5 (84.9) & NA & 0.001 \\
\hline \multicolumn{6}{|l|}{ Mean (SE) lung function } \\
\hline $\mathrm{FEV}_{1}(\%$ predicted) & $100.9(1.7) \dagger$ & $103.6(2.4) \dagger$ & $93.4(2.6)^{*}$ & $100(2.1)$ & 0.018 \\
\hline DRS & $1.5(0.3)$ & $3.1(1.1)^{*}$ & $6.6(2.9)^{*}$ & $0.94(0.22)$ & 0.001 \\
\hline
\end{tabular}

due to asthma, a current exacerbation, or peak flow readings reduced from the subject's best recordings. ${ }^{6}$

\section{Spirometric tests}

Children withheld short acting $\beta_{2}$ agonists for 4 hours before testing. Height and weight were recorded and baseline spirometric tests performed (Med-Graphics AS-600 St Paul, MN, USA). Subjects performed three reproducible forced expiratory manoeuvres wearing nose clips to measure forced expiratory volume in 1 second $\left(\mathrm{FEV}_{1}\right)$ and vital capacity $(\mathrm{VC})$.

\section{Saline challenge}

Hypertonic saline $(4.5 \%)$ challenge was performed as described previously. ${ }^{5}$ Briefly, $4.5 \%$ saline was inhaled for doubling time periods (30 seconds, 1, 2, and 4 minutes) from a DeVilbiss 2000 ultrasonic nebuliser (Oregon, Pike, PA, USA) and a Hans Rudolph 2700, two way non-rebreathing valve box (Hans Rudolph Inc, Kansas City, USA) with a rubber mouthpiece and nose clips. ${ }^{5}$ The nebuliser output was $1.8 \mathrm{ml} / \mathrm{min}$ and

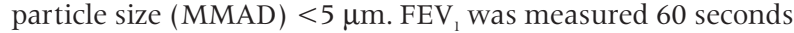
after each saline dose. The test was stopped when the $\mathrm{FEV}_{1}$ had fallen by $\geqslant 20 \%$ or 20 cumulative minutes of nebulisation time had elapsed. If $\mathrm{FEV}_{1}$ had fallen $\geqslant 20 \%$ during the challenge, $\beta_{2}$ agonist was administered using a metered dose inhaler. The dose of saline delivered to the patient was determined by weighing the nebuliser cup and tubing before and after the challenge.

Supplemental $\beta_{2}$ agonist was administered if the FEV fell by more than $10 \%$ or if it fell to the exclusion level during the induction. Nebulisation was continued after there was clinical and lung function improvement.

\section{Sputum induction}

Sputum induction was conducted concurrently with the saline challenge as described previously. ${ }^{5}$ Before the hypertonic saline challenge was commenced the sputum induction procedure was explained to the subject. The technician demonstrated how to cough and clear the throat in order to propel mucus from the lungs into the mouth, and then to empty these contents into a sterile sputum container. Subjects were asked to rinse their mouth with water before the procedure to help eliminate squamous cell contamination of the sputum sample. They were asked to cough between each dose of nebulised saline to clear their throat and expectorate into the container. This procedure continued until an adequate sample containing $>0.5 \mathrm{ml}$ visible mucocellular material was obtained. If a satisfactory sputum sample was not obtained at the time the $\mathrm{FEV}_{1}$ had fallen $\geqslant 20 \%$, nebulisation with $4.5 \%$ saline was continued for 4 minute periods once the FEV 1 had returned to within $10 \%$ of baseline.

\section{Sputum processing}

Sputum was selected from saliva and processed as described elsewhere..$^{5-7}$ Briefly, sputum was treated by adding four volumes of $0.1 \%$ dithiothreitol (DTT-Sputolysin 10\%; Calbiochem Corp, La Jolla, CA, USA) and mixed by rotating for 30 minutes at $37^{\circ} \mathrm{C}$, followed by four volumes of phosphate buffered saline (PBS). The suspension was filtered through a $60 \mu \mathrm{m}$ nylon gauze (Millipore, North Ryde, NSW Australia) and a total cell count of leucocytes and viability was determined. The cell suspension was centrifuged at $200 \mathrm{~g}$ for 10 minutes and supernatant was aspirated and stored at $-70^{\circ} \mathrm{C}$. The cell pellet was resuspended in PBS to attain a concentration of $1 \times 10^{6}$ cells $/ \mathrm{ml}$ and $70 \mu \mathrm{l}$ placed into cups of a Shandon III cytocentrifuge (Shandon Cytospin, Sewickey, PA, USA) for slide preparation.

The quality of induced sputum samples was assessed based on the presence of an adequate number of cells for enumeration, the presence of pulmonary macrophages on the slide, and the proportion of squamous epithelial cells. This gave a quality score ranging from 0 (poor quality) to 6 (good quality sample). ${ }^{5}$

\section{Cytochemistry}

A differential cell count was obtained by counting 400 non-squamous cells on slides fixed with methanol and stained with May Grunwald Giemsa. Eosinophils were enumerated as the percentage of 400 cells on slides fixed with methanol and stained with Chromotrope 2R. Metachromatic cells were 
Table 2 Induced sputum results and clinical asthma pattern

\begin{tabular}{|c|c|c|c|c|c|}
\hline & Infrequent episodic & Frequent episodic & Persistent & Healthy control & $p$ value \\
\hline Total cell count $\left(\times 10^{6} / \mathrm{ml}\right)$ & $1.7(0.8,3.7)$ & $1.7(0.8,4.8)$ & $2.6(0.9,7.1)$ & $1.9(0.9,2.7)$ & 0.38 \\
\hline Squamous (\%) & $9.9(3.8,34.6)$ & $24.1(2.7,57.6)$ & $18.1(4.4,50.4)$ & $16.5(4.1,35.0)$ & 0.94 \\
\hline Quality & $6(5,6)$ & $6(4,6)$ & $6(5,6)$ & $6(4,6)$ & 0.80 \\
\hline Neutrophil (\%) & $29.2(0.1,47.8)$ & $27.3(17.1,58.1)$ & $32.0(19.0,66.0)$ & $36.6(17.0,53.3)$ & 0.73 \\
\hline Eosinophil (\%) & $1.5(0,7.0) \dagger$ & $2.3(0.5,11.3)^{*}$ & $3.8(1.7,14.0)^{*}$ & $1.0(0.3,1.8)$ & 0.002 \\
\hline Macrophage (\%) & $53.4(35.8,74.4) \dagger$ & $47.0(25.3,71.5)$ & $27.0(15.8,56.0)$ * & $53.5(40.0,69.0)$ & 0.01 \\
\hline Lymphocyte (\%) & $0.3(0,1.1)$ & $1.0(0,1.5)$ & $0.5(0,1)$ & $0.5(0,2)$ & 0.03 \\
\hline Epithelial (\%) & $2.0(0.5,6) \dagger$ & $6.0(0.3,10.5)$ & $5.0(1.8,17)^{*}$ & $2.5(1.0,5.8)$ & 0.04 \\
\hline Mast cells (\%) & $0(0,0)$ & $0(0,0)$ & $0(0,0)$ & $0(0,0)$ & 0.85 \\
\hline $\mathrm{ECP}(\mathrm{ng} / \mathrm{ml})$ & $113(43,391) \dagger$ & $220(44,718)$ & $375(124,1258)$ * & $139(48,262)$ & 0.0003 \\
\hline
\end{tabular}

counted as the percentage of 1500 cells on slides fixed in Carnoy's solution and stained with acidic toluidine blue. Cell counts were performed using coded slides by investigators blinded to the clinical characteristics of the subjects.

\section{Fluid phase measurements}

The concentration of ECP was determined in sputum supernatant by radioimmunoassay (ECP RIA; Kabi Pharmacia Diagnostics AB, Uppsala, Sweden) with standard curves based on dilutions of purified ECP. The limit of detection of the fluid phase ECP was $2 \mathrm{ng} / \mathrm{ml}$.

\section{Analysis of data}

Data were analysed using STATA for Windows Version 5.0 (Stata Corp, College Station, Texas, US). Airways responsiveness was assessed as the dose-response slope and was log transformed for analysis with results presented as mean (SE). Cell counts were expressed as the median and interquartile range (IQR). Fluid phase measures were log transformed for analysis. Group comparisons were conducted using analysis of variance with Bonferonni post hoc testing for normally distributed variables and Kruskall-Wallis testing for nonparametric data. Associations between variables were examined using Pearson's correlation coefficient. A multivariate analysis was performed using logistic regression with eosinophil count as the outcome variable. Eosinophil count was not normally distributed and was therefore categorised as $<2.5 \%$

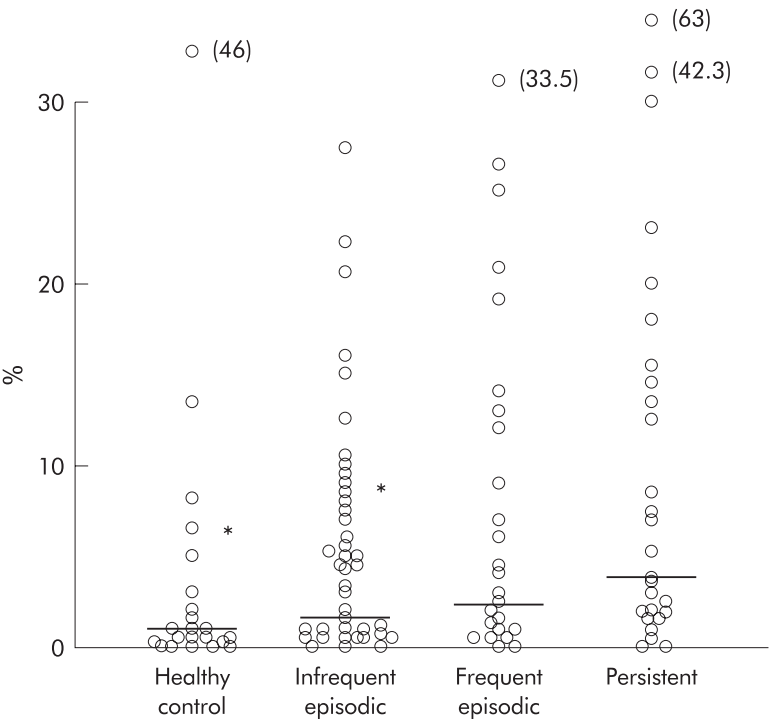

Figure 1 Sputum eosinophils (\%) for clinical asthma pattern. Bars are medians; ${ }^{*} p<0.05 v$ persistent. and $\geqslant 2.5 \%$ based on previous normal values. ${ }^{6}$ Explanatory variables included clinical asthma pattern, treatment, age, and sex. A p value of $<0.05$ was considered significant.

\section{RESULTS}

The clinical characteristics of the children with asthma $(n=146)$ and the healthy controls $(n=37)$ are shown in table 1. The children were aged between 6 and 17 years; $49 \%$ reported having infrequent episodic symptoms in the past year, $27 \%$ had frequent episodic asthma, and $24 \%$ had persistent asthma symptoms. The children with persistent asthma were more symptomatic at the time of testing, with more children reporting night waking due to asthma $(p=0.001)$ and morning waking with asthma $(p=0.0003$, table 1$)$. The children with persistent asthma also had mildly reduced lung function ( $93 \%$ predicted; $p=0.02$, table 1 ). Airway responsiveness to $4.5 \%$ saline was assessed in 108 children (59\%). There was a gradation in airway responsiveness to hypertonic saline, with a progressive and significant increase in dose-response slope as clinical severity increased $(p=0.001$, table 1$)$.

Most children with persistent and frequent episodic asthma were taking inhaled corticosteroids $(83 \%$ and $82 \%$, respectively) compared with $58 \%$ children with infrequent episodic asthma $(\mathrm{p}=0.006$, table 1$)$

\section{Induced sputum}

Adequate sputum samples were obtained from $78 \%$ of children. These samples were of good quality (quality score 6/6, IQR 5,6) and had minimal squamous contamination (median 16\%, IQR 3,40) with no differences in these parameters between subject groups (table 2, p>0.05). Children with asthma had higher levels of eosinophils than controls $(p<0.05)$. Other parameters were similar between asthmatic and control children. With increasing clinical asthma there was a significant increase in sputum eosinophils (fig $\mathrm{l}, \mathrm{p}=0.002$ ) and sputum eosinophil cationic protein (ECP; $\mathrm{p}=0.003$, table 2 ). Sputum eosinophils and ECP were also significantly increased in persistent asthma and frequent episodic asthma compared with controls. Children with persistent asthma had significantly increased levels of desquamated bronchial epithelial cells (table 2, $\mathrm{p}=0.04 v$ controls). Children with infrequent episodes of asthma had similar cell counts to healthy controls $(\mathrm{p}>0.05)$. Mast cells were uncommon, being present in $11 \%$ of children with asthma and $5 \%$ of healthy controls $(p=0.66)$. Increasing treatment intensity was also associated with increasing airway inflammation, specifically an increase in sputum eosinophils and desquamated bronchial epithelial cells, $(\mathrm{p}<0.05$, table 3$)$. In a regression analysis to assess determinants of increased sputum eosinophils, the odds of sputum eosinophilia increased with increasing clinical asthma (odds ratio (OR) infrequent episodic asthma 2.72; frequent episodic OR 4.49; 
Table 3 Induced sputum results and asthma treatment

\begin{tabular}{|c|c|c|c|c|}
\hline & No treatment & $\begin{array}{l}\text { Inhaled preventer } \\
\text { (SCG or ICS) }\end{array}$ & $\begin{array}{l}\text { Oral corticosteroid and } \\
\text { inhaled preventer }\end{array}$ & $\mathrm{p}$ value \\
\hline Total cell count $\left(\times 10^{6} / \mathrm{ml}\right)$ & $1.8(0.9,2.8)$ & $2.1,(0.8,5.4)$ & $2.5(1.1,4.4)$ & 0.40 \\
\hline Squamous (\%) & $21.3(4.8,39.5)$ & $11.0(3.8,36.1)$ & - & 0.37 \\
\hline Quality & $6(4,6)$ & $6(5,6)$ & $6(6,6)$ & 0.69 \\
\hline Neutrophil (\%) & $34.3(15.5,56.5)$ & $29.5(17.5,53.5)$ & $34.0(28.0,57.0)$ & 0.43 \\
\hline Eosinophil (\%) & $1.0(0,2)$ & $3.5(1.0,9.0)$ & $7.0(1.5,12.5)$ & $<0.001$ \\
\hline Macrophage (\%) & $55.0(36.0,70.5)$ & $47.6(23.5,71.6)$ & $32.0(12.5,47.5)$ & 0.009 \\
\hline Lymphocyte (\%) & $0.5(0,1.5)$ & $0.51(0,1.41)$ & $0.5(0.5,1.0)$ & 0.83 \\
\hline Epithelial (\%) & $2.5(0.8,6.0)$ & $3.5(0.6,9.0)$ & $9.5(6.0,24.5)$ & 0.01 \\
\hline Mast cells (\%) & $0(0,0)$ & $0(0,0)$ & $0(0,0)$ & 0.23 \\
\hline ECP (ng/ml) & $134.7(50.3,302.5)$ & $194.8(58.1,777.4)$ & $320.8(228.8,616.1)$ & 0.16 \\
\hline
\end{tabular}

Values are median (IQR).

$S C G=$ cromoglycate; ICS=inhaled corticosteroid; $E C P=$ eosinophil cationic protein.

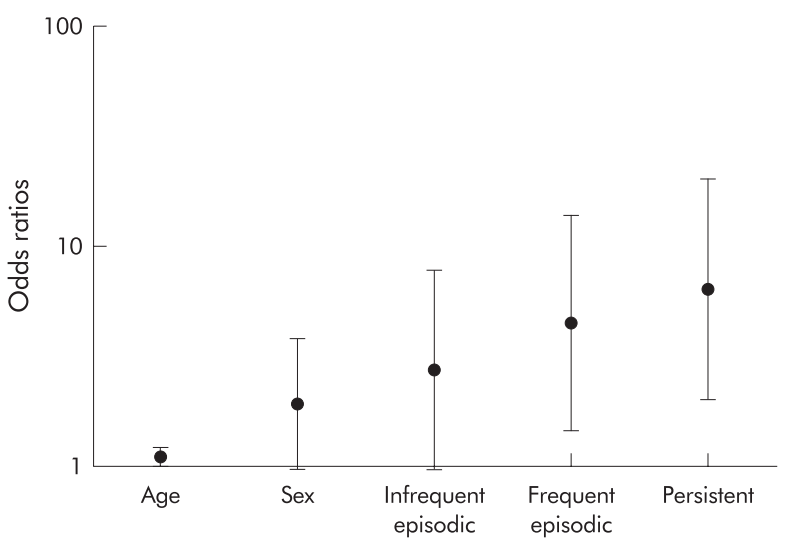

Figure 2 Log odds $(95 \% \mathrm{Cl})$ of increased eosinophils for asthma pattern.

Table 4 Multiple logistic regression for determinants of sputum eosinophilia in childhood asthma $(n=171)$

\begin{tabular}{llll}
\hline & Odds ratio $(95 \% \mathrm{Cl})$ & $\mathrm{p}$ value* \\
\hline Infrequent episodic asthma & $1.69(0.54$ to 5.29$)$ & 0.364 \\
Frequent episodic asthma & $2.35(0.65$ to 8.55$)$ & 0.195 \\
Persistent asthma & $3.15(0.83$ to 12.01$)$ & 0.092 \\
Inhaled corticosteroids & $2.34(1.04$ to 5.26$)$ & 0.041 \\
Age & $1.11(0.99$ to 1.24$)$ & 0.080 \\
Sex & $1.89(0.95$ to 3.79$)$ & 0.07 \\
\hline
\end{tabular}

*Wald statistic.

Significance of model: $p=0.0001$; area under $R O C$ curve $=0.729$.

persistent asthma OR 6.35, fig 2) and with increasing treatment intensity ( $\mathrm{p}=0.0005$, table 4$)$.

Children with currently symptomatic asthma $(n=64)$ had significantly increased eosinophils $(p=0.05)$, ECP $(p=0.011)$, and desquamated bronchial epithelial cells $(p=0.04$, table 5$)$ compared with asymptomatic children, irrespective of clinical asthma grouping. Airway responsiveness and lung function were similar in symptomatic and asymptomatic children $(\mathrm{p}>0.05$, table 5$)$.

There were no significant correlations between sputum eosinophils and $\mathrm{FEV}_{1}(r=-0.08)$ or degree of airway responsiveness $(r=0.22)$.

\section{DISCUSSION}

In this study we have established that, as background clinical asthma increases, there is an increase in the degree of sputum eosinophilia, sputum ECP, and desquamation of bronchial epithelial cells. Airway hyperresponsiveness to hypertonic saline was both more common and more severe with increasing
Table 5 Asthma variables and current (past 2 weeks) asthma symptoms

\begin{tabular}{llll}
\hline & $\begin{array}{l}\text { Current } \\
\text { symptoms }\end{array}$ & Asymptomatic & p value \\
\hline Eosinophils (\%) & $3.25(1.0,11.6)$ & $1.75(0.0,7.0)$ & 0.05 \\
Epithelial (\%) & $5.00(1.0,14.0)$ & $2.63(0.5,7.4)$ & 0.04 \\
ECP $(\mathrm{ng} / \mathrm{ml})$ & $302.5(82,957)$ & $107.4(45,395)$ & 0.011 \\
DRS & $1.27(0.2,3.2)$ & $1.14(0.5,2.8)$ & 0.802 \\
FEV $1 \%$ predicted) & $100(86,108)$ & $101.9(93,109)$ & 0.108 \\
\hline
\end{tabular}

Values are medians (IQR).

$E C P=$ eosinophil cationic protein; $D R S=$ dose-response slope;

$\mathrm{FEV}_{1}=$ forced expiratory volume in 1 second.

clinical asthma. In addition, the intensity of asthma treatment that was required showed a similar association with increasing sputum eosinophilia.

We undertook a number of measures to ensure a valid assessment of the relationship between clinical asthma and airway inflammation. Firstly, a large number of children were studied to allow sufficient numbers for multivariate analysis and to avoid the possibility of a type 2 error. Children were recruited from primary care as well as from specialist clinics in order to obtain a group with a range of asthma. Airway inflammation was assessed using the non-invasive but valid technique of sputum induction ${ }^{278}{ }^{10}$ which was well tolerated and successful in this group of children. Airway hyperresponsiveness was assessed by hypertonic saline. This is an indirectly acting stimulus that correlates with the degree of airway epithelial inflammation in asthma, ${ }^{11}$ particularly airway mast cells. ${ }^{511}$ The nebulisation time varied, depending on the FEV response, and in each child was less than 8 minutes. Variations in nebulisation times over 15-20 minutes are reported to alter sputum neutrophils, but not eosinophils. The varying nebulisation time is unlikely to have influenced the results of this study since the primary outcome measure was sputum eosinophils, and we used shorter nebulisation times than are known to affect cell counts.

There are several different ways to assess clinical asthma. ${ }^{12}$ These include the frequency of wheezing episodes over the past 12 months, current (past week) symptom control, maintenance treatment requirements, lung function measures such as $\mathrm{FEV}_{1}$ or airway hyperresponsiveness, and composite measures as used in adult asthma guidelines. In this study the pattern of clinical asthma was assessed using the frequency of symptomatic episodes over the past 12 months. This classification corresponds with the current paediatric asthma management guidelines ${ }^{1}$ and other published reports. ${ }^{9}{ }^{13}$ Studies in adults that have assessed asthma using similar methods also found that clinical asthma correlated with airway inflammation. ${ }^{14}$ No previous paediatric studies have used this assessment technique when relating clinical asthma 
to airway inflammation. In one study there was a tendency to a relationship between sputum eosinophils and clinical asthma assessed using a composite severity score. ${ }^{8}$

In adults several studies have reported a relationship between inflammatory cells and the degree of airflow obstruction measured by $\mathrm{FEV}_{1}$ or $\mathrm{FEV} / \mathrm{VC}$ ratio. ${ }^{10-17}$ In children no such relationship was found (in this study or previously ${ }^{2}$ ). This may be because $\mathrm{FEV}_{1}$ is near normal in most children with asthma, except during an exacerbation. In the current study $94.5 \%$ of children with asthma had an FEV $>80 \%$ predicted. When lung function is reduced, as occurs in a severe asthma exacerbation ${ }^{18}$ or in severe chronic asthma, ${ }^{48}$ then sputum eosinophils are correlated with the degree of airflow obstruction. Airway hyperresponsiveness has been found to be weakly associated with sputum inflammation in some ${ }^{51016}$ but not all studies. ${ }^{15} 19$

The relationship between asthma treatment and airway inflammation has been assessed in three studies. Two studies which used type of treatment (inhaled corticosteroid (ICS) $v$ no ICS) failed to find a relationship between treatment requirements and airway inflammation, ${ }^{24}$ whereas another study found that sputum eosinophil levels were lower in children taking ICS than in non-ICS users. ${ }^{20}$ In our study we included children with a range of treatment intensities, from none to ICS through to oral corticosteroids. Using this approach, we found that ICS use was positively associated with airway inflammation. Since the outcome variable (sputum eosinophils) was represented as a categorical variable, the regression model examined the association between ICS use and the presence of sputum eosinophilia. Children with more frequent episodes of asthma are more likely to be treated with ICS (table 1). While this improves clinical asthma and may reduce sputum eosinophils, it is not established that sputum eosinophils are reduced to the normal range by this treatment. Indeed, our earlier study found persistent sputum eosinophilia in children treated with high doses of ICS. ${ }^{6}$ The degree to which airway inflammation responds to corticosteroids, both within and between patients, is an important issue that needs to be addressed in future studies.

We have also examined the relationship between current symptoms and airway inflammation. Earlier we reported on the relationship between sputum eosinophils and current symptom control (past 2 weeks) in a group of children recruited from specialist clinics. ${ }^{6}$ These children had predominantly persistent asthma. Although there was a tendency for increased eosinophils with increasing symptom levels, the relationship failed to reach statistical significance. The results of the present study, in a larger group of children with episodic as well as persistent asthma, indicate that currently symptomatic children had significantly higher degrees of sputum eosinophils, ECP, and bronchial epithelial cells than asymptomatic children. However, there was a considerable overlap between the groups and, at an individual level, there is a poor relationship between symptom free days and sputum eosinophils in children recruited from a hospital based paediatric respiratory clinic. ${ }^{24}$ Other studies have also cautioned against using current symptoms to assess severity ${ }^{21}$ and adjust treatment. ${ }^{22}$ This suggests that, while airway inflammation is a determinant of current symptomatic asthma, the relationship is less strong than for the pattern of asthma over the previous 12 months. An important corollary of this that needs prospective study is the possibility that suppression of eosinophilic inflammation may be required to achieve current symptom control.

In addition to eosinophilic inflammation, we observed that the proportion of bronchial epithelial cells in the sputum of children with asthma increased as clinical asthma status increased. Bronchial epithelial desquamation is classically recognised as the presence of Creola bodies in sputum. ${ }^{23}$ The epithelium is now considered a major focus of airway damage in asthma. Epithelial loss occurs when the desmosomal connections between basal and columnar epithelial cells are disrupted, ${ }^{24}{ }^{25}$ and this can be induced by eosinophil granule proteins. ${ }^{26}$ Increased bronchial epithelial cells have been reported in persistent asthma, ${ }^{6}$ with environmental exposure to mite allergen, ${ }^{27}$ with late asthmatic responses during allergen challenge, ${ }^{23} 28$ and during acute severe exacerbations of asthma.$^{18}$ This is the first study to relate epithelial desquamation to the pattern of asthma in children. Boulet has previously correlated epithelial loss with the degree of airway remodelling (subepithelial fibrosis) in asthma. ${ }^{29}$ Our observations of increasing eosinophilic inflammation and ECP with increasing clinical asthma provide a mechanism for the increased sputum epithelial cells in frequent and persistent asthma, and indicate ongoing airway damage in these conditions.

In conclusion, we have shown that the clinical pattern of asthma is related to the degree of airway inflammation and that, as background clinical asthma status increases, there is increasing airway inflammation that is characterised by sputum eosinophilia and bronchial epithelial desquamation. The results support the assessment of asthma by frequency of wheezing episodes over the past 12 months when determining anti-inflammatory treatment requirements, and indicate that current symptoms are less closely related to sputum eosinophilia. These observations validate the severity assessment recommended in current asthma guidelines and identify an opportunity for the use of induced sputum when currently symptomatic patients are not controlled by initial treatment.

\section{ACKNOWLEDGEMENT}

This study was funded by the National Health and Medical Research Council of Australia.

\section{Authors' affiliations}

P G Gibson, J L Simpson, H Powell, Department of Respiratory and Sleep Medicine, and Hunter Medical Research Institute, John Hunter Hospital, Newcastle, 2310 NSW, Australia

R Hankin, The John Hunter Children's Hospital, Newcastle, 2310 NSW, Australia

R L Henry, School of Women's and Children's Health, The University of New South Wales, Randwick, 2031 NSW, Australia

\section{REFERENCES}

1 Warner JO, Naspitz CK. Third International Pediatric Consensus statement on the management of childhood asthma. International Pediatric Consensus Group. Pediatr Pulmonol 1998:25:1-17.

2 Wilson NM, Bridge P, Spanevello A, et al. Induced sputum in children: feasibility, repeatability, and relation of findings to asthma severity. Thorax 2000;55:768-74.

3 Piacentini GL, Bodini A, Costella S, et al. Exhaled nitric oxide and sputum eosinophil markers of inflammation in asthmatic children. Eur Respir J 1999;13:1386-90.

4 Wilson NM, James A, Uasuf C, et al. Asthma severity and inflammation markers in children. Pediatr Allergy Immunol 2001;12:125-32.

5 Gibson PG, Wlodarczyk JW, Hensley M, et al. Epidemiological association of airway inflammation with asthma symptoms and airway hyperresponsiveness in childhood. Am J Respir Crit Care Med 1998; 158:36-41.

6 Cai Y, Carty K, Henry RL, et al. Persistence of sputum eosinophilia in children with controlled asthma when compared with healthy children. Eur Respir J 1998;11:848-53

7 Gibson PG, Henry RL, Thomas P. Noninvasive assessment of airway inflammation in children: induced sputum, exhaled nitric oxide, and breath condensate. Eur Respir J 2000;16:1008-15.

8 Grootendorst DC, van den Bos JW, Romeijn JJ, et al. Induced sputum in adolescents with severe stable asthma. Safety and the relationship of cell counts and eosinophilic cationic protein to clinical severity. Eur Respir J 1999; 13:647-53

9 Kable S, Henry R, Sanson-Fisher R, et al. Childhood asthma: can computers aid detection in general practice? Br J Gen Pract 2001;51:112-6.

10 Pin I, Gibson PG, Kolendowicz R, et al. Use of induced sputum cell counts to investigate airway inflammation in asthma. Thorax 1992;47:25-9.

11 Gibson PG, Saltos N, Borgas T. Airway mast cells and eosinophils correlate with clinical severity and airway hyperresponsiveness in corticosteroid-treated asthma. J Allergy Clin Immunol 2000; 105:752-9. 
12 Cockcroft DW, Swystun VA. Asthma control versus asthma severity. J Allergy Clin Immunol 1996;98:1016-8.

13 Rosier MJ, Bishop J, Nolan T, et al. Measurement of functional severity of asthma in children. Am J Respir Crit Care Med 1994;149:1434-41.

14 Bousquet J, Chanez P, Lacoste JY, et al. Eosinophilic inflammation in asthma. N Engl J Med 1990;323:1033-9.

15 Crimi E, Spanevello A, Neri $M$, et al. Dissociation between airway inflammation and airway hyperresponsiveness in allergic asthma. Am J Respir Crit Care Med 1998;157:4-9.

16 Pizzichini E, Pizzichini MMM, Efthimiadis A, et al. Measuring airway inflammation in asthma: eosinophils and eosinophil cationic protein in induced sputum compared with peripheral blood. J Allergy Clin Immunol 1997;99:539-44.

17 Ronchi MC, Piragino C, Rosi E, et al. Role of sputum differential cell count in detecting airway inflammation in patients with chronic bronchia asthma or COPD. Thorax 1996;51:1000-4.

18 Norzila M, Fakes K, Henry RL, et al. IL-8 secretion and neutrophil recruitment accompanies induced sputum eosinophil activation in children with acute asthma. Am J Respir Crit Care Med 2000;161:769-74.

19 Ireland MJ, Wanklyn SAR, Philips IP, et al. Non-invasive assessment of bronchial inflammation in asthma: no correlation between eosinophilia of induced sputum and bronchial responsiveness to inhaled hypertonic saline. Clin Exp Allergy 1997;24:940-5.

20 Zimmerman B, Silverman FS, Tarlo SM, et al. Induced sputum: comparison of postinfectious cough with allergic asthma in children. $J$ Allergy Clin Immunol 2000;105:495-9.
21 Osborne ML, Vollmer WM, Pedula KL, et al. Lack of correlation of symptoms with specialist-assessed long-term asthma severity. Chest 1999; 115:85-91.

22 Sont JK, van Krieken JHJM, Evertse CE, et al. Relationship between the inflammatory infiltrate in bronchial biopsy specimens and clinical severity of asthma in patients treated with inhaled steroids. Thorax 1996;51:496-502.

23 Tateishi K, Motojima S, Kushima A, et al. Comparison between allergen-induced and exercise-induced asthma with respect to the late asthmatic response, airway responsiveness, and Creola bodies in sputum. Ann Allergy Asthma Immunol 1996;77:229-37.

24 Montefort S, Roberts JA, Beasley R, et al. The site of disruption of the bronchial epithelium in asthmatic and non-asthmatic subjects. Thorax 1992;47:499-503

25 Ordonez C, Ferrando R, Hyde DM, et al. Epithelial desquamation in asthma: artifact or pathology? Am J Respir Crit Care Med 2000;162:2324-9.

26 Montefort S, Herbert CA, Robinson C, et al. The bronchial epithelium as a target for inflammatory attack in asthma. Clin Exp Allergy 1992:22:511-20.

27 Piacentini GL, Vicentini L, Mazzi P, et al. Mite-antigen avoidance can reduce bronchial epithelial shedding in allergic asthmatic children. Clin Exp Allergy 1998:28:561-7.

28 Silvestri M, Oddera S, Sacco O, et al. Bronchial and bronchoalveolar inflammation in single early and dual responders after allergen inhalation challenge. Lung 1997;175:277-85.

29 Boulet LP, Laviolette M, Turcotte $H$, et al. Bronchial subepithelial fibrosis correlates with airway responsiveness to methacholine. Chest $1997 ; 112: 45-52$.

\section{LUNG ALERT}

\section{Prophylactic zanamivir: effective prevention of influenza A and B in household contacts of laboratory proven influenza}

- Monto AS, Pichichero ME, Blanckenberg SJ, et al. Zanamivir prophylaxis: an effective strategy for the prevention of influenza types A and B within households. J Infect Dis 2002;186:1582-8

7 his double blind, multicentre study performed over a single winter season recruited 1291 household contacts ( $>5$ years old) of 485 patients presenting with an influenza-like illness (occurring when influenza was known to be circulating locally). Household contacts were randomised to receive zanamivir $10 \mathrm{mg}$ or placebo for 10 days within 36 hours of symptom onset in the index case (who did not receive antiviral treatment). Symptomatic laboratory confirmed influenza (confirmed by a fourfold rise in anti-influenza antibody, viral culture or PCR) during the period of prophylaxis occurred in at least one household contact in $4 \%$ of households treated with zanamivir compared with $19 \%$ of households given placebo $(\mathrm{p}<0.001)$, representing an $81 \%$ protective efficacy. Similar efficacy was achieved with both influenza A (78\%) and B (85\%). There was no evidence of development of resistance in isolates and there were no episodes of bronchospasm noted among the 661 contacts receiving zanamivir, although only $11 \%$ had an underlying respiratory condition and severe persistent asthma was an exclusion criteria.

Influenza vaccination remains the mainstay of prophylaxis, but this study suggests that prophylactic zanamivir has a role particularly in households with at-risk individuals where vaccination uptake is low.

D D Creer

v.creer@virgin.net 